\title{
IMPLANTAÇÃO DO FRAMEWORK DE SOFTWARE SCRUM EM EMPRESA PARA MELHORAR A GESTÃO DE PROJETOS
}

Tamiris Fernanda Malacrida, Francisco Virginio Maracci, Cássia Alves Perego

Universidade do Oeste Paulista - UNOESTE, Faculdade de Informática de Presidente Prudente, Presidente Prudente, SP. E-mail: tamirismalacrida@gmail.com.

\section{RESUMO}

O objetivo dessa pesquisa foi realizar a proposta de implantação do framework Scrum para gestão de projetos juntamente com o uso de ferramentas para gestão da configuração (controle de mudanças e versão) em uma empresa de desenvolvimento de software, com intuito de organizar o processo de desenvolvimento de software, a gestão de mudanças, o controle de versões e, consequentemente, aumentar a satisfação ao cliente e qualidade do produto final. Os dados coletados foram compilados em uma planilha com o auxílio de um software estatístico, onde foram analisados através de gráficos para obtenção do cenário real, realizando um comparativo do período antecessor e pós implantação.

Palavras-chave: Scrum; Gerenciamento de Projeto; Gestão da Configuração; Melhoria Contínua; Engenharia de Software;

\section{IMPLEMENTATION OF SCRUM SOFTWARE FRAMEWORK IN COMPANY TO IMPROVE PROJECT MANAGEMENT}

\begin{abstract}
The objective of this research was to implement the proposed Scrum framework for project management together with the use of tools for configuration management (change control and versioning) in a software development company, in order to organize the development process Software, change management, version control and hence increase customer satisfaction and end product quality. The collected data were compiled in a spreadsheet with the aid of statistical software, where they were analyzed through graphs to obtain the real scenario, comparing the predecessor period and post implantation period.
\end{abstract}

Keywords: Scrum; Project Management; Configuration Management; Continuou Improvement; Software Engineering; 


\section{INTRODUÇÃO}

Diante da atual expansão tecnológica, o mercado exige que as empresas de desenvolvimento de software sejam rápidas e eficazes na entrega dos projetos. Além de prazos curtos é necessária uma adaptação rápida perante mudanças bruscas que possam vir a ocorrer ao longo de um projeto, sujeitando-as adquirir meios inovadores para atenderem tais mudanças sem grandes impactos.

Com intuito de organizar os processos e oferecer melhor estrutura para desenvolvimento de software de alta qualidade, foi criada a Engenharia de Software, que é uma aproximação sistemática para a produção de software que considera o custo para o desenvolvimento, cronograma e questões de confiabilidade, assim como as necessidades dos clientes e desenvolvedores (SOMMERVILLE, 2010).

O framework Scrum é uma metodologia ágil para gerenciamento de projetos em que os requisitos sofrem mudanças constantes e, portanto, necessita um planejamento e condução do projeto diferenciado. O Scrum é um framework, ágil, simples e leve, utilizado para a gestão do desenvolvimento de produtos complexos imersos em ambientes complexos. Scrum é embasado no empirismo e utiliza uma abordagem iterativa e incremental para entregar valor com frequência e, assim, reduzir os riscos do projeto (SABBAGH, 2013).

Sua forma ágil de trabalhar deve-se ao fato de que o Scrum não define práticas específicas e detalhadas a serem seguidas rigorosamente, ele entende que as práticas necessárias para o sucesso do projeto são muito específicas para cada contexto, não podendo assim ser prescritas. Segundo Mike Cohn (2011), o Scrum possui diante de todo seu processo, doze princípios ágeis, os quais se resumem brevemente em satisfazer o cliente da melhor forma possível e ser flexível para adequar as mudanças necessárias rapidamente. Outro grande princípio é a entrega de software de valor em um prazo máximo de trinta dias para o cliente. Portanto, é indispensável a comunicação entre as pessoas, a colaboração do cliente, uma equipe motivada e com atenção continua quanto a excelência técnica.

O Scrum na prática é organizado da seguinte forma, os projetos são divididos em ciclos (basicamente, semanais ou mensais) chamados de Sprints. Um Sprint é representado por um conjunto de atividades que devem ser executadas sem folgas e com tempo pré-determinado. As funcionalidades a serem implementadas em um projeto são mantidas em uma lista que é conhecida como Product Backlog.

No início de cada Sprint, faz-se um Sprint Planning Meeting, ou seja, uma reunião de planejamento na qual o Product Owner prioriza os itens do Product Backlog e a equipe seleciona as atividades que ela será capaz de implementar durante o Sprint que se inicia. As tarefas alocadas em um Sprint são transferidas do Product Backlog para o Sprint Backlog, que é uma lista de tarefas que a equipe se compromete a fazer em um Sprint.

A cada dia de um Sprint, a equipe faz uma breve reunião (normalmente de manhã), chamada Daily Scrum. Ao final de um Sprint, a equipe apresenta as funcionalidades implementadas em uma reunião que finaliza o Sprint. Finalmente, faz-se uma retrospectiva do sprint e a equipe parte para o planejamento do próximo. Assim reinicia-se o ciclo, como é ilustrado na figura 1. 
Figura 1: Ciclo do Sprint.

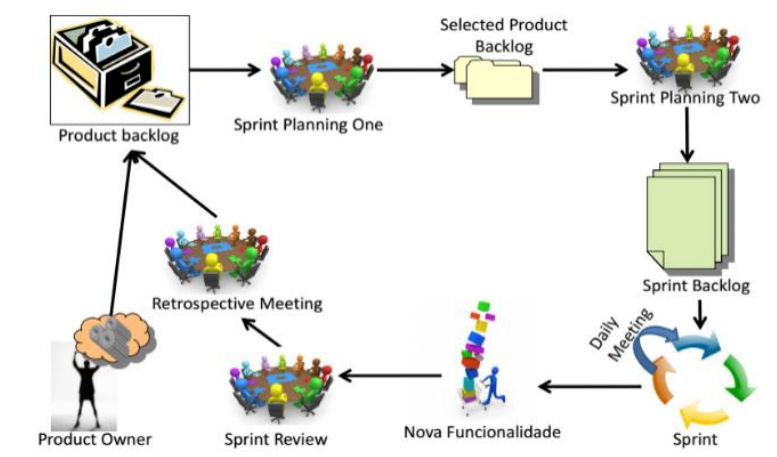

Fonte: Material de Engenharia de Software - Professor Francisco Maracci.

Durante o desenvolvimento de um Sprint os artefatos de projetos normalmente sofrem alterações necessitando um controle de mudanças e versões. Portanto, é desejado que os artefatos produzidos (código-fonte, documento de requisitos, planos de testes, entre outros) sejam controlados durante todo o processo de desenvolvimento. A arte de coordenar o desenvolvimento de software e gerenciar os artefatos produzidos é a Gestão da Configuração, que visa identificar, organizar e controlar modificações nos artefatos (itens de configuração) software que está sendo construído por uma equipe de programação. É um processo de extrema importância para que as empresas possam manter o seu desenvolvimento de software controlado e evite retrabalho por perdas de resultados de atividades que já foram anteriormente concluídas (PRESSMAN, 2010).

Segundo Leonardo Molinari (2011) a gestão da configuração de software previne que o processo de software se torne intratável, controlando as alterações e mantendo a integridade do sistema ao identificar e controlar a configuração do software, hardware e das ferramentas que forem usadas durante todo o ciclo de desenvolvimento.

\section{METODOLOGIA}

O cenário típico de chamados da empresa, sempre foi questionado pela quantidade de atendimentos urgentes que surgiam durante o processo de desenvolvimento, com isso as tarefas quase nunca eram concluídas no prazo. Fazendo com que alguns projetos não cumpriam o prazo acordado, levando a certas despesas com retrabalhos, consequentemente o custo do projeto se tornava mais alto que o orçado, contendo mudanças constantes dos requisitos, além de alguns casos, até acontecerem o cancelamento de projeto. Diante dessa situação, surgiu em grande escala a necessidade de organizar o desenvolvimento de software da empresa. Nessa ocasião foi abordada a implantação do Framework Scrum para organização dos processos e desenvolvimento, no qual o desenvolvedor trabalhando com essa metodologia, consegue ter foco, agilidade e organização no projeto desenvolvido.

Juntamente com Scrum foi adotada a tecnologia de gestão da configuração, uma ferramenta que faz o controle mudanças e versões do código-fonte, garantindo todos os históricos de alterações que o projeto sofreu no decorrer de todo o desenvolvimento.

A proposta foi implantada em duas etapas, imediatamente após a adesão, foi instalada a ferramenta de gestão da configuração para que todas as alterações em códigos-fontes fossem armazenadas seus históricos evitando assim perca de informações.

A ferramenta adotada para a realizar a gestão da configuração e garantir o repositório de alterações do código fonte, é o Tortoise SVN.

O Tortoise SVN é um cliente open-source gratuito para a plataforma Windows, administra arquivos e diretórios no decorrer do tempo. Os arquivos são armazenados em um repositório central. Toda e qualquer alteração realizada em alguma aplicação, é armazenada. 
Isso permite a você recuperar versões antigas de seus arquivos e examinar o histórico de como, quando e por quem seus dados foram modificados.

Figura 2: Menu do Tortoise SVN.

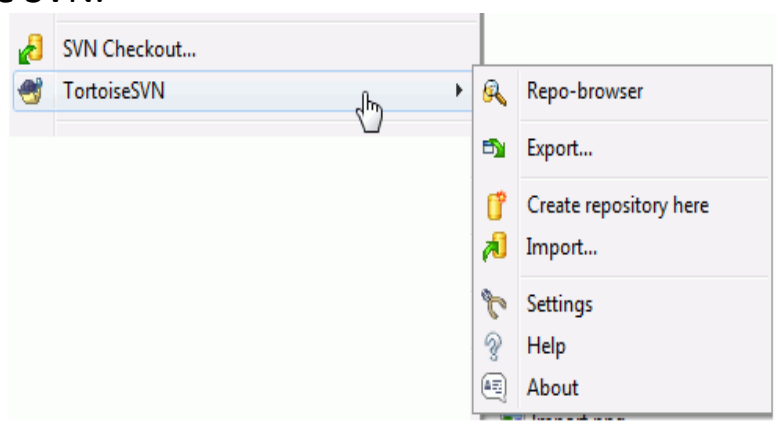

Fonte: dados trabalhados pelo autor.

Já em uma segunda etapa foi implantado o framework Scrum, devido a necessidade da empresa finalizar demandas urgentes, a metodologia Scrum foi adotada somente para novos projetos, os antigos foram finalizados da forma como haviam iniciado.

Idealizando que essa proposta é para que a o processo da empresa trabalhe sempre buscando a melhoria contínua dos processos.

\section{RESULTADOS}

A proposta foi implantada com o objetivo de eliminar ou diminuir os problemas que ocorrem, principalmente, pela falta de organização no desenvolvimento de projetos e controle de mudanças e versões necessitando refazer atividades consideradas concluídas.

Antes da implantação como pode-se observar a figura 3, o cenário de chamados da empresa é bem crítico.

Figura 3: Resultados antes da implantação do projeto.

\begin{tabular}{|l|r|r|}
\hline & Nivel de Prioridade (Qtde) & Nivel de Prioridade(\%) \\
\hline ANALISEIESTES & 12 & 8 \\
\hline ATENDIMENTO & 16 & 11 \\
\hline BRIEFING - URGENTE & 69 & 47 \\
\hline BRIEFING - ALTO & 35 & 24 \\
\hline BRIEFING - MEDIO & 3 & 2 \\
\hline BRIEFING - BAIXO & 1 & 1 \\
\hline CANCELADO & 0 & 0 \\
\hline ERRO - SISTEMA & 2 & 1 \\
\hline ERRO - USUÁRIO & 8 & 5 \\
\hline TOTAL & 146 & 100 \\
\hline
\end{tabular}



Fonte: dados trabalhados pelo autor.

No decorrer de 4 meses de implantação e adequação das rotinas para utilização do framework Scrum, pode-se observar uma melhoria bem significativa nos chamados urgentes que ocorreram no período, conforme mostrado na figura 4. 
Figura 4: Resultados 4 meses após implantação do projeto.

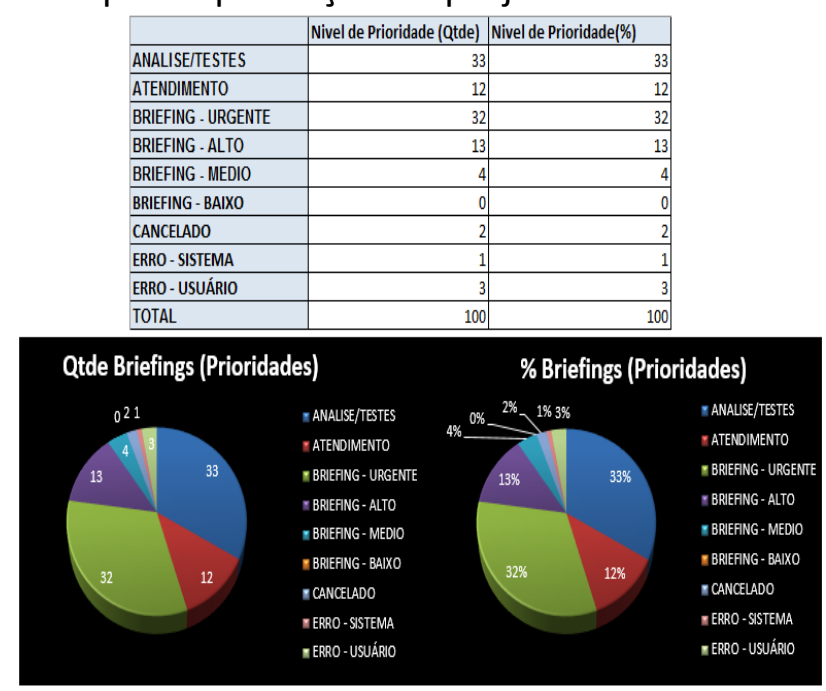

Fonte: dados trabalhados pelo autor.

Diante dos resultados expressivos, pode observar que em um curto espaço de tempo, houve uma melhora expressiva nas atividades desenvolvidas, reduzindo retrabalho para os desenvolvedores, aumentando as rotinas de validações e testes, o qual é parte da solução proposta, consequentemente aumentando a satisfação dos clientes, onde não precisam ficar em contato com desenvolvedores por problemas e chamados urgentes que muitas vezes demoravam os processos empresarias.

\section{CONCLUSÃO}

Como idealizado no início desse artigo muitas empresas sofrem com a má organização no desenvolvimento de software, após implantação de todo o trabalho proposto, pode-se verificar que a implantação do framework teve impacto positivo para os processos de gerenciamento de configuração, escopo, tempo e qualidade no desenvolvimento de softwares, com base nas informações demonstradas no terceiro capítulo.

É facilmente identificar que a agilidade nos processos de desenvolvimento de software, com tarefa traçada do que precisa ser feito, em determinado tempo, e os constantes feedbacks com os clientes contribuem muito positivamente para a qualidade do software.

O feedback recebido pelas avaliações realizadas junto aos membros da equipe de desenvolvimento aponta a aceitação pela metodologia, os quais, interessados em contribuir e melhorar o processo, oferecem sugestões pessoais de melhorias.

Mediante comparação do antes e depois do processo de desenvolvimento de software, ficaram visíveis as melhorias trazidas pelo uso da metodologia em conjunto com a ferramenta que trabalha na gestão da configuração, como a melhora no acompanhamento do projeto, a realização de testes e validações feitos logo após o término do projeto e a melhora na comunicação entre os membros da equipe, além da rastreabilidade de alterações garantidas pela gestão da configuração.

\section{REFERÊNCIAS}

SABBAGH, Rafael. SCRUM: Gestão Ágil para Projetos de Sucesso, 5a Edição, 2013.

COHN, Mike. Desenvolvimento de Software com Scrum. Aplicando Métodos Ágeis com Sucesso, Edição 2011.

PRESSMAN, Roger S. Engenharia de Software, 6ạ Edição, 2010. 
MOLINARI, Leonardo. Testes de Software. Produzindo Sistemas Melhores e Mais Confiáveis. 4ạ Edição, 2011.

KERZNER, Harold. GESTÃo DE PROJETOS: As Melhores Práticas, Edição 2006.

KOSCIANSKI, A., SOARES, M. S. Qualidade de Software: Aprenda as metodologias e técnicas mais modernas para o desenvolvimento de software. 2. ed. São Paulo: Novatec, 2007.

SOMMERVILLE, lan. Engenharia de Software, 6o Edição, 2004. 